\title{
К диагностике видов рода Trollius L. (Ranunculaceae) Алтайской горной страны
}

\section{To the diagnosis of species of the genus Trollius L. (Ranunculaceae) of the Altai mountain country}

\author{
Эрст А. С. ${ }^{1,2}$, Луферов А. Н. ${ }^{3}$, Трошкина В. И. ${ }^{1}$ \\ Erst A. S. ${ }^{1,2}$, Luferov A. N. ${ }^{3}$, Troshkina V. I. ${ }^{1}$ \\ ${ }^{1}$ Центральный Сибирский ботанический сад СО РАН, г. Новосибирск, Россия. E-mail: erst_andrew@yahoo.com \\ ${ }^{2}$ Томский государственный университет, г. Томск, Россия \\ ${ }^{3}$ Первый Московский государственный медичинский университет им. И. М. Сеченова, г. Москва, Россия. \\ E-mail:luferovc@mail.ru \\ ${ }^{1}$ Central Siberian Botanical Garden, Siberian Branch of the RF Academy of Sciences, Novosibirsk, Russia \\ ${ }^{2}$ Tomsk State University, Tomsk, Russia \\ ${ }^{3}$ I. M. Sechenov First Moscow State Medical University, Pharmaceutical Natural Science Department, Moscow, Russia
}

\begin{abstract}
Peферат. Для Алтайской горной страны приведено 3 вида Trollius (Ranunculaceae), которые относятся к 2 секциям. Составлен оригинальный ключ для их определения и таксономический конспект, включающий номенклатурные цитаты, сведения о типовых образцах, распространении в регионе и общем распространении каждого вида, уточнена принадлежность видов к секциям.
\end{abstract}

Ключевые слова. Trollius, Ranunculaceae, Алтайская горная страна, конспект, систематика.

Summary. The article provides information about the taxonomic composition of the genus Trollius in the Altai mountainous country. 3 species are revealed: T. asiaticus, T. altaicus, T. dschungaricus, for which the systematic position is indicated, the nomenclature and morphological descriptions are given, the geographical distribution is characterized. Along with the known diagnostic features of these species, new, previously unused features of the structure of their vegetative and generative organs are proposed: the ratio of the length and width of the lobes and segments of the leaf blades, the outlines of their edges (the degree of dismemberment, the shape of the teeth and recesses), the number of veins of the petals below the nectar fossa and above it.

Key words. Trollius, Ranunculaceae, Altai mountain country, synopsis, systematics.

Род Trollius L. - купальница включает около 35 видов, распространенных во внетропических регионах Северного полушария. Hegemone часто рассматривается как отдельный род (Tamura, 1995). Опушение рыльца и белые (розовые, фиолетовые) чашелистики являются одними из важнейших характеристик, которыми этот род отличается от Trollius. Род характеризуется ярко выраженными цветами оранжевого или желтого цвета, лепестками, тройчатыми или глубоко 3-лопастными листьями (Kadota, 1987). Представители рода купальница отличаются морфологической структурой цветка: лепестки разделены на пластинку, ямку (nectarostigma) и коготок (Wang et al., 2010). Отношение длины лепестков к тычинкам считается одним из наиболее важных признаков для разграничения видов (Шипчинский, 1937; Сипливинский, 1972; Луферов, 2004). A. Doroszewska (1974) разделила род на 7 секций. Они в основном естественные, но морфологические различия не существенные, чтобы принимать их в полном объеме (Tamura, 1995).

В России известны около 19-20 видов (Luferov et al., 2018). Наибольшее видовое разнообразие наблюдается в Сибири (12 видов); 11 видов Trollius (Friesen, 2012) были ранее указаны для этого региона, из которых мы признаем 9, T. sajanensis (Malyschev) Sipl. является синонимом T. asiaticus L. Многие 
виды, которые были недавно описаны в России, требуют более детального изучения и подтверждения видовой самостоятельности (Luferov et al., 2018).

Виды рода Trollius Алтайской горной страны, согласно работе Doroszewska (1974), относятся к двум секциям: Trollius Doroszewska (T. altaicus C.A. Mey, T. dschungaricus Regel), и Longipetala Doroszewska (T. asiaticus L.). Первая секция характеризуется «petals elongated, convex, thickened, shorter than sepals» (Doroszewska, 1974), вторая группа морфологически характеризуется «petals linear, flat, thin, longer than sepals or nearly equal to them». Работы по молекулярной филогении не включают все группы и большинство видов (Despres et al., 2003; Wang et al., 2010). В работе L. Despres (2003) рассматриваются T. altaicus и T. asiaticus, которые входят в одну кладу и разные подклады молекулярно-филогенетического дерева. В публикации Wei Wang с соавторами (2010) в анализ включен только T. asiaticus, a T. dschungaricus и T. altaicus не исследовался молекулярно-филогенетическими методами. В связи с малоизученностью всех трех видов молекулярными методами, сложно рассуждать об их таксономическом родстве и принадлежности к известным группам.

Рассматриваемые нами виды купальницы относятся к разным группам по классификации Doroszewska (1974). T. altaicus и $T$. dschungaricus входят в одну группу, но имеют ряд важных отличий. T. altaicus характеризуется 5 сегментами базальных листьев (для $T$. dschungaricus характерно рассечение на 3-5 долей листовой пластинки), тонкой, не мясистой текстурой листа, матовой поверхностью (у T. dschungaricus пластинка листа толстоватая, слегка мясистая, часто с глянцевитой поверхностью). Важными, ранее не рассматриваемыми признаками, которые могут быть использованы при диагностики T. altaicus и T. dschungaricus, являются край листовой пластинки и форма зубчиков (T. altaicus характеризуется короткими, по краю дуговидно выпуклыми, на верхушке острыми или слегка притупленными зубчиками; в отличие от этого вида, для $T$. dschungaricus характерны мелкие остроконечные или остроконечные зубчики) (табл.).

Таблица

Сравнение видов рода Trollius из Алтайской горной страны по таксономически значимым признакам

\begin{tabular}{|c|c|c|c|}
\hline Признак & T. altaicus & T. dschungaricus & T. asiaticus \\
\hline $\begin{array}{l}\text { Высота побегов, } \\
\text { см }\end{array}$ & $\begin{array}{l}15-60, \text { при плодоношении } \\
80-100\end{array}$ & $\begin{array}{l}5-40, \text { при плодоношении } \\
60-70\end{array}$ & 5-75, при плодоношении 90 \\
\hline $\begin{array}{l}\text { Число стеблевых } \\
\text { листьев }\end{array}$ & $2-4$ & $2-4$ & $2-6$ \\
\hline $\begin{array}{l}\text { Количество сег- } \\
\text { ментов } \\
\text { (у T. dschungaricus } \\
\text { долей) базальных } \\
\text { листьев }\end{array}$ & 5 & $3-5$ & 5 \\
\hline $\begin{array}{l}\text { Консиситенция } \\
\text { листовой } \\
\text { пластинки } \\
\end{array}$ & Тонкая, не мясистая & $\begin{array}{l}\text { Толстоватая, слегка мя- } \\
\text { систая }\end{array}$ & Тонкая, не мясистая \\
\hline $\begin{array}{l}\text { Форма сегментов } \\
\text { (у T. dschungari- } \\
\text { cus: долей) листо- } \\
\text { вой пластинки }\end{array}$ & Широкоромбическая & $\begin{array}{l}\text { Широкообратнояйцевид- } \\
\text { ная, почковидная }\end{array}$ & Ромбическая \\
\hline $\begin{array}{l}\text { Край листовой } \\
\text { пластинки }\end{array}$ & $\begin{array}{l}\text { Доли листовых сегментов } \\
\text { сближенные и нередко } \\
\text { заходящие друг на друга } \\
\text { своими неравно-зубча- } \\
\text { то-пильчатыми краями. } \\
\text { Зубцы обычно короткие, по } \\
\text { краю дуговидно выпуклые, } \\
\text { на верхушке острые, реже } \\
\text { слегка притупленные }\end{array}$ & $\begin{array}{l}\text { Пластинки по краю немно- } \\
\text { го надрезанные на корот- } \\
\text { кие городчато-зубчатые } \\
\text { лопасти: зубцы с мелкими } \\
\text { остроконечиями или окру- } \\
\text { глые }\end{array}$ & $\begin{array}{l}\text { Доли листовых сегментов } \\
\text { расставленные в стороны с } \\
\text { хорошо заметными выем- } \\
\text { ками между ними, по краю } \\
\text { неравно-зубчато-пильчатые. } \\
\text { Зубцы чаще продолгова- } \\
\text { то-треугольные с прямыми } \\
\text { или слегка дуговидными } \\
\text { краями, на верхушке зао- } \\
\text { стренные, реже острые }\end{array}$ \\
\hline
\end{tabular}


Таблица (продолжение)

\begin{tabular}{|c|c|c|c|}
\hline Признак & T. altaicus & T. dschungaricus & T. asiaticus \\
\hline $\begin{array}{l}\text { Длина черешка } \\
\text { базального листа, } \\
\text { см }\end{array}$ & $4-25(35)$ & $4-10(15)$ & $4-35(45)$ \\
\hline $\begin{array}{l}\text { Диаметр цветка, } \\
\text { см }\end{array}$ & $2.5-4$ & $3.5-6$ & $3-5$ \\
\hline $\begin{array}{l}\text { Окраска } \\
\text { чашелистика }\end{array}$ & $\begin{array}{l}\text { Желтый или желтовато- } \\
\text { оранжевый }\end{array}$ & $\begin{array}{l}\text { Желтый или светло- } \\
\text { желтый; снаружи иногда } \\
\text { слегка красноватый }\end{array}$ & $\begin{array}{l}\text { Оранжевый или } \\
\text { красновато-оранжевый }\end{array}$ \\
\hline $\begin{array}{l}\text { Длина } \\
\text { чашелистика, мм }\end{array}$ & $12-19$ & $17-29$ & $14-24$ \\
\hline $\begin{array}{l}\text { Ширина } \\
\text { чашелистика, мм }\end{array}$ & $\begin{array}{l}\text { 12-25 (наружные } \\
\text { чашелистики), 7-18 } \\
\text { (внутренние чашелистики) }\end{array}$ & $12-32$ & $12-28$ \\
\hline $\begin{array}{l}\text { Количество } \\
\text { чашелистиков }\end{array}$ & $10-15$ & $5-20$ & $10-20$ \\
\hline $\begin{array}{l}\text { Форма } \\
\text { чашелистика }\end{array}$ & $\begin{array}{l}\text { Наружные чашелистики } \\
\text { широкообратнояйцевидные } \\
\text { или почковидные; вну- } \\
\text { тренние: ромбовидные или } \\
\text { узкообратнояйцевидные, с } \\
\text { клиновидным основанием } \\
\text { и суженные к верхушке }\end{array}$ & $\begin{array}{l}\text { Широкообратнояйцевид- } \\
\text { ные или эллипсовидные }\end{array}$ & Обратнояйцевидные \\
\hline Окраска лепестка & $\begin{array}{l}\text { Оранжевая или } \\
\text { желто-оранжевая }\end{array}$ & Желтая & $\begin{array}{l}\text { Оранжевая или } \\
\text { оранжево-красная }\end{array}$ \\
\hline $\begin{array}{l}\text { Длина лепестка, } \\
\text { мм }\end{array}$ & 9-18 & $5-8$ & $12-24$ \\
\hline $\begin{array}{l}\text { Ширина лепестка, } \\
\text { мм }\end{array}$ & $0.8-1.2$ & $1.5-2$ & $2.5-4(6)$ \\
\hline $\begin{array}{l}\text { Количество } \\
\text { лепестков }\end{array}$ & $8-16(19)$ & $8-14$ & $18-30(40)$ \\
\hline Форма лепестков & Линейные & $\begin{array}{l}\text { Обратнояйцевидные или } \\
\text { лопатчатые }\end{array}$ & $\begin{array}{l}\text { Продолговато- } \\
\text { эллиптические }\end{array}$ \\
\hline $\begin{array}{l}\text { Количество жилок } \\
\text { лепестка }\end{array}$ & $3-5$ & $\begin{array}{l}3 \text { (под нектарной ямкой) - } \\
5 \text { (выше нектарной ямки) }\end{array}$ & $7-17$ \\
\hline $\begin{array}{l}\text { Форма верхушки } \\
\text { лепестка }\end{array}$ & $\begin{array}{l}\text { Округлая, реже обру- } \\
\text { бленная или с небольшой } \\
\text { выемкой }\end{array}$ & $\begin{array}{l}\text { Округлая или обрубленная, } \\
\text { реже с небольшой выемкой }\end{array}$ & Округлая, реже острая \\
\hline $\begin{array}{l}\text { Отношение длины } \\
\text { чашелистика к } \\
\text { длине лепестка }\end{array}$ & $\begin{array}{l}\text { Лепестки короче } \\
\text { чашелистиков в 2-3 раза }\end{array}$ & $\begin{array}{l}\text { Лепестки короче чашели- } \\
\text { стиков в 4-7 раз }\end{array}$ & $\begin{array}{l}\text { Лепестки немного короче } \\
\text { или почти равны } \\
\text { чашелистикам }\end{array}$ \\
\hline $\begin{array}{l}\text { Отношение длины } \\
\text { лепестка к длине } \\
\text { тычинки }\end{array}$ & $\begin{array}{l}\text { Лепестки длиннее } \\
\text { тычинок на 1-4 мм, реже } \\
\text { почти равны им }\end{array}$ & $\begin{array}{l}\text { Лепестки равны или на 1-3 } \\
\text { мм короче тычинок }\end{array}$ & $\begin{array}{l}\text { Лепестки в } 2-3 \text { раза } \\
\text { длиннее тычинок }\end{array}$ \\
\hline $\begin{array}{l}\text { Форма нектарной } \\
\text { ямки }\end{array}$ & Узкоэллиптическая & Узкоэллиптическая & $\begin{array}{l}\text { Широкоэллиптическая или } \\
\text { обратнояйцевидная }\end{array}$ \\
\hline $\begin{array}{l}\text { Расстояние от } \\
\text { основания лепест- } \\
\text { ка до нектарной } \\
\text { ямки, мм } \\
\end{array}$ & $1-1,5$ & $0,8-1$ & $2-3$ \\
\hline $\begin{array}{l}\text { Окраска столбика } \\
\text { и рыльца }\end{array}$ & $\begin{array}{l}\text { Столбики и рыльца } \\
\text { черно-пурпурные или } \\
\text { красновато-фиолетовые }\end{array}$ & $\begin{array}{l}\text { Столбики и рыльца } \\
\text { желтоватые или } \\
\text { темно-пурпурные }\end{array}$ & $\begin{array}{l}\text { Столбики и рыльца } \\
\text { желтоватые }\end{array}$ \\
\hline
\end{tabular}


«Проблемы ботаники Южной Сибири и Монголии» - XVIII Международная научно-практическая конференция

Таблица (окончание)

\begin{tabular}{|l|l|l|l|}
\hline \multicolumn{1}{|c|}{ Признак } & \multicolumn{1}{|c|}{ T. altaicus } & \multicolumn{1}{c|}{ T. dschungaricus } & \multicolumn{1}{c|}{ T. asiaticus } \\
\hline $\begin{array}{l}\text { Поверхность } \\
\text { листовки }\end{array}$ & $\begin{array}{l}\text { С резко выступающими } \\
\text { поперечными жилками }\end{array}$ & $\begin{array}{l}\text { Почти гладкая с едва } \\
\text { заметными жилками }\end{array}$ & $\begin{array}{l}\text { Жилки слегка } \\
\text { выступающие }\end{array}$ \\
\hline $\begin{array}{l}\text { Длина листовки, } \\
\text { мм }\end{array}$ & $12-17$ & $9-12$ & $8-11$ \\
\hline $\begin{array}{l}\text { Длина стилодия, } \\
\text { мм }\end{array}$ & $2-3$ & $1,8-2,2$ & $0,5-1$ \\
\hline $\begin{array}{l}\text { Форма стилодия и } \\
\text { его ориентация в } \\
\text { пространстве }\end{array}$ & $\begin{array}{l}\text { Тонкий, прямой или от } \\
\text { основания изогнутый } \\
\text { наружу, на верхушке } \\
\text { загнутый к центру плода }\end{array}$ & $\begin{array}{l}\text { Прямой или дуговидно } \\
\text { изогнутый наружу }\end{array}$ & $\begin{array}{l}\text { Дуговидно-изогнутый } \\
\text { внутрь или прямой, } \\
\text { отклоненный наружу }\end{array}$ \\
\hline
\end{tabular}

Важным признаком, который может быть использован при идентификации видов, является диморфизм чашелистиков (в пределах одного цветка возможна различная форма чашелистиков). T. dschungaricus и T. altaicus характеризуются этим признаком в отличии от T. asiaticus, который имеет все одинаковые чашелистики. Очень важным признаком для идентификации таксонов является длина стилодия. T. altaicus отличается наиболее длинными стилодиями, что отличает этот вид от двух других. T. asiaticus характеризуется широким ареалом, в пределах которого отмечается морфологический ряд изменчивости. Этот вид отличается тонкой, не мясистой консистенцией листовой пластинки, ромбической формой сегментов базального листа, расставленными долями листовых сегментов, продолговато-треугольными зубцами листа с прямыми или слегка дуговидными краями, заостренными на верхушке, чашелистиками равными лепесткам и с очень короткими стилодиями листовок (у двух других видов стилодии гораздо длиннее). Следует отметить, что встречаются образцы растений, совмещающие диагностические признаки листьев T. altaicus и T. asiaticus: доли и зубцы по краю иногда могут быть как с прямыми, так и с дуговидно-выпуклыми боковыми сторонами, а верхушки заостренными и острыми. Для T. dschungaricus наиболее характерными являются желтоватые столбики и рыльца, однако известны случаи их темно-пурпурной окраски (табл.). Можно предположить, что такое сочетание признаков у образцов с промежуточными характеристиками свидетельствует о возможном скрещивании разных видов в зонах контакта. Следует отметить, что на разных стадиях развития длина фолликулов и стилодиев сильно отличается, у всех трех видов в начальной стадии стилодии вытягиваются, но к моменту плодоношения длина самого фоликула становится длиннее длины стилодия, исключение составляет T. altaicus. Поэтому некоторые виды требуют более детального исследования (Степанов, 2018). У трех изученных нами видов бутоны и начальные стадии распускания цветка нередко характеризуются разнообразной окраской чашелистиков и лепестков: от светло-желтой, темно-желтой, зеленоватой до желто-оранжевой с розовыми, красноватыми, иногда фиолетовыми оттенками. Указанные особенности морфологического строения имеют важное диагностическое значение и использованы в настоящей статье для составления ключа для определения изученных видов. Обращается также внимание на случаи совмещения у некоторых образцов структурных признаков, свойственных разным видам, что важно учитывать при их идентификации. Для выяснения причин такой изменчивости необходимы дальнейшие исследования с применением различных методов.

\section{Ключ для определения видов рода Trollius Алтайской горной страны}

1. Лепестки в числе $18-40$, в 1,5-2 раза длиннее тычинок и почти равны или немного короче чашелистиков. Медовая ямка широкоовальная или обратнояйцевидная, располагается в 2-3 мм от основания лепестка. Число жилок у лепестков 7-17. Длина стилодия 0,5-1 мм. Доли листовых сегментов расставленные в стороны с хорошо заметными выемками между ними, по краю неравно-зубчато-пильчатые. Зубцы чаще продолговато-треугольные с прямыми или слегка дуговидными краями, на верхушке заостренные, реже острые T. asiaticus 
+ Лепестки в числе 8-16 (19), по длине почти равны тычинкам или немного длиннее их и более, чем в 2 раза короче чашелистиков. Медовая ямка узкоовальная, располагается в $0,8-1,5$ мм от основания лепестка. Число жилок у лепестков 3-5. Стилодии более длинные. Листовые пластинки иного строения

2. Листовые пластинки тонкие, не мясистые, рассеченные на 5 широкоромбовидных сегментов с продолговато-ланцетными, сближенными и нередко заходящими друг на друга долями, по краю неравно-зубчато-пильчатыми. Зубцы обычно короткие, по краю дуговидно выпуклые, на верхушке острые, реже слегка притупленные. Чашелистики диморфные: из них: наружные широкообратнояйцевидные или почковидные; внутренние: ромбовидные или узкообратнояйцевидные, с клиновидным основанием и суженные к верхушке. Лепестки 9-18 мм дл., линейные, длиннее пестиков или равны им. Столбики и рыльца черно-пурпурные, фиолетовые или красноватые. Листовки 12-17 мм дл. Стилодии 2-3 мм дл.

T. altaicus

+ Листовые пластинки толстоватые, слегка мясистые, 3-5-раздельные; доли широкообратнояйцевидные или почковидные, по краю немного надрезанные на короткие городчато-зубчатые лопасти: зубцы с мелкими остроконечиями, реже округлые. Чашелистики мономорфные: широкообратнояйцевидные или эллипсовидные. Лепестки 5-8 мм дл., обратнояйцевидные или лопатчатые, с округлой верхушкой и слегка завернутыми внутрь краями, обычно короче пестиков. Столбики и рыльца желтоватые или темно-пурпурные. Листовки 9-12 мм дл. Стилодии 1,8-2.2 мм дл. T. dschungaricus

\section{ЛИТЕРАТУРА}

Луферов А. Н. Таксономический конспект лютиковых (Ranunculaceae) Дальнего Востока России // Turczaninowia, 2004. - Т. 7, №1. - С. 5-84.

Сипливинский В. Н. Род Trollius L. на Севере и Востоке Азии // Новости сист. высш. раст. Л.: Наука, 1972. T. 9. - C. 163-182.

Степанов Н. В. Новый вид Trollius L. (Ranunculaceae) из Кузнецкого Алатау // Систематические заметки по материалам Гербария Томского государственного университета, 2018. - № 117. - С. 40-45.

Шипчинский Н. В. Купальница - Trollius L. // Флора CCСР. М.-Л.: Изд-во Академии наук CCCP, 1937. T. 7. - C. 42-54.

Despres L., Gielly L., Redoutet B., Taberlet P. Using AFLP to resolve phylogenetic relationships in a morphologically diversified plant species complex when nuclear and chloroplast sequences fail to reveal variability // Mol. Phylogenet. Evol., 2003. - Vol. 27, № 2. - P. 185-196.

Doroszewska A. The genus Trollius - A taxonomical study // Monogr. Bot. Pol. Akad. Nauk. Warszawa, 1974. - Vol. 41. - P. 1-167.

Friesen N. V. Trollius L. In: Flora of Siberia. - Enfield (NH), USA; Plymouth, UK: Science Publ., Inc., 2003. - Vol. 6. - P. 98-103.

Kadota Y. Genus Trollius L. (Ranunculaceae) in Japan // Bull. Natn. Sci. Mus., Tokyo. Ser. B., 1987. - Vol. 13, № 3. - P. 107-121.

Luferov A. N., Erst A. S., Luferov D. N., Shmakov A. I., Wang W. 2018. The genus Trollius (Ranunculaceae) in the Russian Far East // Turczaninowia, 2018. - Vol. 21, № 2. - P. 110-116. DOI: 10.14258/turczaninowia.21.2

Tamura M. Trollius L. // In: Hiepko P. (Ed.) Die Natürlichen Pflanzenfamilien, Band 17a, IV. Duncker und Humblot. Berlin, 1995. - P. 238-244.

Wang W., Hu H., Xiang X.-G., Yu S.-X., Chen Z.-D. Phylogenetic placements of Calathodes and Megaleranthis (Ranunculaceae): Evidence from molecular and morphological data // Taxon, 2010. - Vol. 59, № 6. - P. 1712-1720. DOI: $10.2307 / 41059868$ 